\title{
Militancia partidaria y militancia fragmentada en la jurisprudencia del Tribunal Supremo de Elecciones: análisis crítico de la resolución 2434-E8-2021
}

Mauricio Blanco-Gamboa*

https://doi.org/10.35242/RDE 2021326

Nota del Consejo Editorial

Recepción: 21 de mayo de 2021.

Revisión, corrección y aprobación: 5 de julio de 2021.

Resumen: Los partidos políticos son estructuras esenciales en el sistema democrático costarricense, pero con el pasar de los años, las formas de vinculación entre aquellos y las personas han cambiado significativamente, a tal punto que hoy los partidos políticos atraviesan una crisis de legitimidad. Sin embargo, en materia jurisprudencial, los cambios han tendido a ser restrictivos con los tipos de participación, que no necesariamente involucran una relación duradera con la agrupación política. Para comprender mejor el fenómeno, en este artículo se analiza la resolución 2434-E8-2021 del Tribunal Supremo de Elecciones sobre militancia fragmentada a la luz de los principios constitucionales de seguridad jurídica y autorregulación partidaria, así como el diseño constitucional del régimen municipal. Para ello, se analizó diversa jurisprudencia y se encontró que lo resuelto en el voto mencionado configura una interpretación restrictiva que puede poner en riesgo algunos principios del derecho electoral, así como el diseño constitucional de las municipalidades como segundo nivel de gobierno en el país.

Palabras clave: Militancia política / Doble militancia política / Adhesión política / Autorregulación partidaria / Participación política / Derecho electoral / Gobierno local.

Abstract: Political parties are essential structures in the Costa Rican democratic system, but over the years, the way parties and people get involved has greatly changed to the point where political parties go through a crisis of legitimacy. However, in terms of jurisprudential matters, the changes have tended to be restrictive with the types of participation, that do not necessarily involve a lasting relationship with the political group. To better understand the phenomenon, this article analyzes resolution 2434-E8-2021 from the Supreme Electoral Court about fragmented militancy considering the constitutional principles of legal security and party self-regulation, as well as the constitutional design of the municipal regime. In order to do this, diverse jurisprudence was analyzed, and it turned out that what was resolved in the cited resolution configures a restrictive interpretation that can put at risk some principles of electoral law, as well as the constitutional design of municipalities as the second level of government in the country.

Key Words: Political militancy / Double political militancy / Political affiliation / Party self-regulation / Political participation / Electoral law / Local government.

\footnotetext{
* Costarricense, bachiller en derecho, correo maublancog@gmail.com. Egresado del bachillerato en Derecho por la Universidad Latinoamericana de Ciencia y Tecnología y estudiante avanzado del bachillerato en Ciencias de la Comunicación Colectiva en la Universidad de Costa Rica. Asesor de comunicación, presidente del Partido Gente Montes de Oca y regidor suplente del cantón de Montes de Oca.
} 


\section{DERECHO ELECTORAL}

\section{INTRODUCCIÓN}

La función de los partidos políticos es uno de los principales elementos del sistema democrático costarricense. El artículo 98 de la Constitución Política establece la creación de los partidos políticos, y les otorga un carácter absolutamente especial en el sistema político:

Los partidos políticos expresarán el pluralismo político, concurrirán a la formación y manifestación de la voluntad popular y serán instrumentos fundamentales para la participación política. Su creación y el ejercicio de su actividad serán libres dentro del respeto a la Constitución y la ley. Su estructura interna y funcionamiento deberán ser democráticos (Asamblea Nacional Constituyente, 1949, artículo 98).

Esta disposición constitucional origina la regulación actual que da vida a los partidos políticos en el sistema democrático. Sartori resume la definición de un partido político como: "cualquier grupo político que se presenta a elecciones y que puede colocar mediante elecciones a sus candidatos en cargos públicos" (1999, p. 101).

Así, los partidos no existen en abstracto, sino que son grupos de personas organizadas con fines políticos tal y como lo desarrolló el Tribunal Supremo de Elecciones en su voto 1257-E8-2013, en cual menciona que: "su existencia depende de que se nutra de ciudadanos y ciudadanas que opten por asociarse voluntariamente con ese fin y que, por su condición, son quienes detentan la titularidad de la agrupación" (TSE, 2013, Considerando III).

Las personas, sin embargo, pueden interactuar con los partidos políticos de distintas formas. Molina y Pérez (2001) definen diversas variables en función de las cuales las personas ejercen participación política vinculada a partidos políticos: la primera de ellas es ser miembro del partido, para esta existe un acto de inscripción formal que indica la fortaleza de la relación y demuestra que su participación va más allá de una simple identificación con la agrupación.

Adicionalmente, Molina y Pérez (2001) definen variables como participar en la elección de candidaturas, realizar actividades de campaña, financiar al partido o candidaturas o asistir a eventos de campaña. Aguilar (2008) incluso amplía las categorías definiendo variables como identificación 


\section{DERECHO ELECTORAL}

partidaria, intención de voto, opinión hacia el partido político, valoración de las propuestas, entre otras.

En el caso de Costa Rica, los principales términos para describir a las personas que interactúan con partidos políticos, acuñados por el Código Electoral y la jurisprudencia electoral, son "miembro", "afiliado(a)" y "militante".

En la resolución 8690-E8-2012, el Tribunal Supremo de Elecciones abordó el concepto de 'afiliado' a partir del "grado de participación" que pudieran tener las personas. En su momento, señaló lo siguiente:

La condición de afiliado -entendida esta como un "grado
de participación" que permite, de cumplir el sujeto con los
requisitos estatutarios respectivos, acceder a puestos de
representatividad internos de la estructura partidaria-
representa una pública declaración de principios político-
doctrinarios y, en virtud de la adhesión que esto supone, se
constituye en requisito necesario para ejercer cargos partidarios
[Resaltado no es del original]. (Considerando II).

En esta resolución destaca mucho el término "grado de participación", pues el propio Tribunal reconoce que existe todo un espectro que puede describir cómo las personas se vinculan con los partidos políticos. Esta figura se enmarca en la doctrina de Maurice Duverger citada ya en resolución 444 de 1992 (TSE, 444-1992, considerando IV). Para el caso concreto, que habla de ejercer cargos partidarios, se resuelve que la condición de "afiliado" es necesaria, y que trasciende una simple participación práctica, pues supone una adhesión y una declaración pública de los principios político-doctrinarios de los partidos.

Sin embargo, con el tiempo, la línea jurisprudencial del Tribunal Supremo de Elecciones ha puesto en términos absolutos el vínculo que tienen las personas con los partidos para efectos jurídicos. Es decir, o la persona es miembro del partido o no existe ningún grado de participación.

Lo anterior se ilustra de mejor forma en la resolución 2434-E8-2021, objeto de estudio en el presente artículo. Mediante esta, el Tribunal resuelve una opinión consultiva a solicitud del Partido Gente Montes de Oca sobre la militancia simultánea en partidos de diversas escalas. 


\section{DERECHO EIECTORAL}

En esta resolución el Tribunal reafirmó la prohibición que existe en el ordenamiento jurídico costarricense de doble militancia y que ya había desarrollado en la resolución 3261-E8-2008 (reiterada, entre otras, en resolución 6380-E3-2010). Sin embargo, en este voto se amplió sobre qué aspectos constituyen esta "militancia" en los términos que se detallan a continuación. En primer lugar, el Tribunal Supremo de Elecciones afirma que:

...la afiliación a un partido político supone una acción voluntaria de pertenecer a un programa político específico, cuyos ejes programáticos coinciden (en alguna medida) con los propios intereses y la propia visión de mundo, de suerte tal que se tiene una expectativa de un trabajo continuo, desde la sola militancia o desde la incidencia interna en la estructura, para la consecusión [sic] de los fines que han sido condensados en el estatuto partidario.

En otras palabras, la adscripción a un partido, por regla de principio, es un acto que se entiende como el inicio de una relación asociativa estable y perdurable en el tiempo, en tanto solo de esa manera se van produciendo las condiciones necesarias para la estabilización del proyecto político particular. (TSE, 2434-E8-2021, considerando II).

Entonces, en esta primera parte de la resolución, el Tribunal habla de "afiliación" o "adscripción" a un partido político como un acto voluntario y dentro del cual existe la "militancia" como una categoría de comportamiento o acciones que ejercen las personas afiliadas o adscritas al partido.

Más adelante, ante el planteamiento de la exigencia de militancia como requisito para optar por candidaturas de elección popular en algunos partidos, el Tribunal plantea que:

...la militancia no es algo que se "exija" sino, más bien, es el vínculo que surge entre un ciudadano y un partido político cuando el primero, de forma voluntaria, se afilia al segundo o, también, cuando una persona realiza actos que se entienden propios de un afiliado. (TSE, 2434-E8-2021, considerando III). 


\section{DERECHO EIECTORAL}

Por último, unos párrafos más adelante, el Tribunal afirma que la calidad de miembro: "se adquiere con la sola afiliación o con la ejecución de actos que demuestren militancia" (TSE, 2434-E8-2021, Considerando III).

En cuanto a los actos que se consideran como "actos que demuestren militancia", el Tribunal señaló que:

...ejercer alguno de los derechos o el cumplir con alguna de las obligaciones que han sido tipificadas como propias de los integrantes de una agrupación política (numerales 53 y 54 del $\mathrm{CE}$ ) demuestra un acto de afiliación y una militancia directa con el respectivo partido. (TSE, 2434-E8-2021, considerando III).

A manera de resumen, la figura 1 sintetiza esta exposición:

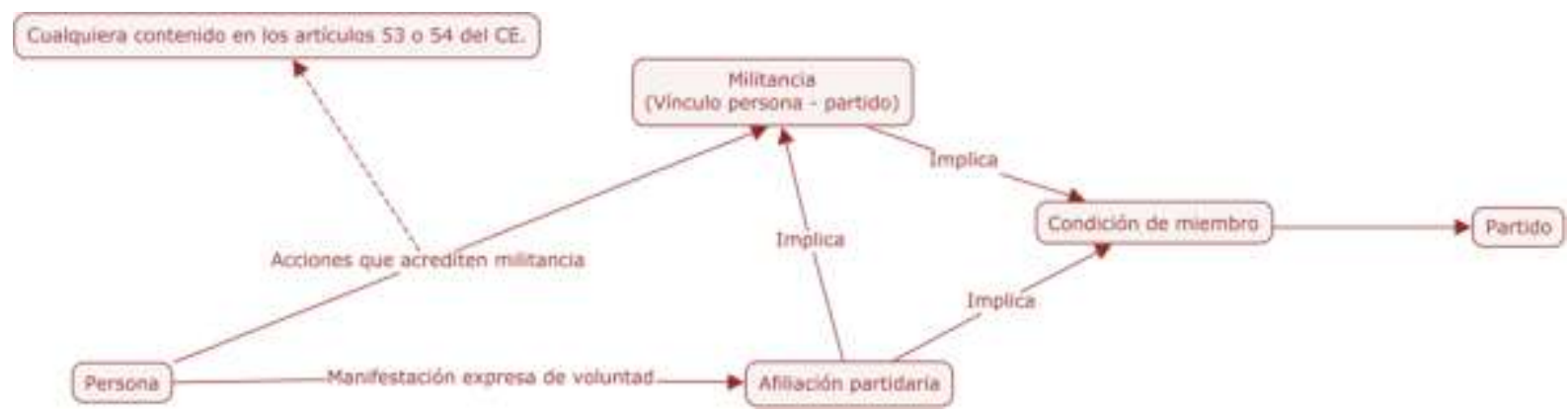

Figura 1. Flujograma de vinculación de las personas con los partidos según voto 2434-E8-2021.

De esta forma, y retomando los "grados de participación", en esta ocasión el Tribunal estipula únicamente las siguientes dos categorías: ser miembro del partido o no serlo. Adicionalmente, el Tribunal establece que no existen excepciones que permitan la doble militancia en partidos de escalas distintas.

El propósito de este artículo es analizar las implicaciones de este voto a la luz de algunos principios electorales y del diseño constitucional del régimen municipal. 


\section{DERECHO ELECTORAL}

\section{VOTO 2434-E8-2021 A LA LUZ DE LOS PRINCIPIOS DE SEGURIDAD JURÍDICA Y AUTORREGULACIÓN PARTIDARIA}

Para comenzar el análisis, es importante destacar algunos principios constitucionales y electorales que deben orientar las interpretaciones en materia electoral. Dentro de estos destaca en la sentencia objeto de análisis una necesidad de revisarla a la luz de los principios de autorregulación partidaria y seguridad jurídica.

\subsection{AUtORREgULACIÓn PARTIDARIA}

Como se indicó al inicio, el artículo 98 constitucional es el que da origen a los partidos políticos en Costa Rica. Este precepto resalta que la actividad partidaria será libre, supeditada únicamente a la Constitución Política y a las leyes. Mandato que fue ampliado por la Sala Constitucional en su voto 5367-99, de hecho, justamente en lo que refiere a este artículo académico. Al respecto, la Sala indicó lo siguiente:

En atención a lo anterior es que el artículo 98 constitucional señala claramente que el ejercicio de la actividad de los partidos políticos es libre, sujeta única pero lógicamente a la Constitución y a la ley. En consecuencia, el Estado no puede incidir en ámbitos partidarios internos que operan bajo el principio de libertad de actuación -y de autorregulación-, como resulta ser lo referente a la admisión y exclusión de partidarios o miembros del partido. Corresponde exclusivamente a la organización interna de los partidos determinar qué personas pueden ser admitidos y establecer cuáles otras deben ser excluidas: entenderlo de otra manera y sostener que el Estado, especialmente en las circunstancias a que se refiere este recurso, puede actuar en esos ámbitos, implicaría una indebida y abusiva intromisión de este. [Resaltado no es del original]. (Considerando VI).

Aquí se encuentra un primer fallo con respecto a la resolución de cita, pues en esta ocasión el Estado está definiendo que todas las personas que ejerzan actuaciones propias de una militancia ostentarían la condición de miembro del partido. Esto va en detrimento de los mecanismos y requisitos que cada partido político haya definido para admitir miembros.

Para citar ejemplos, el estatuto del Partido Frente Amplio en su artículo seis establece que quien desee afiliarse debe recibir un curso sobre el 


\section{DERECHO ELECTORAL}

estatuto del partido (Partido Frente Amplio, 2009). También, el Partido Restauración Nacional establece en su artículo dieciséis que para ser admitido debe haberse aprobado un curso de formación política que defina el Comité Ejecutivo Superior (Partido Restauración Nacional, 2009).

Así las cosas, ambos mecanismos (y cualquier otro que definan los partidos políticos como requisito para la afiliación) quedan vacíos de contenido, pues la simple actividad que se considere militancia le acreditaría la condición de miembro que requiere para diversos efectos jurídicos.

\subsection{SEguRIDAD JURÍdica}

En este caso, cabe recapitular en qué consiste el principio de seguridad jurídica y cómo resultaría aplicable al presente análisis. Haba propone la siguiente definición: "la certidumbre del derecho que exige la perceptibilidad cierta de la norma de derecho" (2007, p. 186). Asimismo, en este informe se destaca que la existencia del Estado de derecho supone un alto grado de seguridad jurídica, lo que reduce las arbitrariedades de quienes tienen que aplicar el derecho.

En el caso concreto, la resolución encuentra aquí un segundo fallo, pues no existe una lista taxativa de acciones que se puedan considerar como "militancia", entonces las personas no podrían estar seguras de cuáles acciones supondrían o no un vínculo de militancia con un partido político.

Como se explicó anteriormente, la resolución alude a los artículos 53 y 54 del Código Electoral, en el sentido de que ejercer los derechos o cumplir las obligaciones allí establecidas suponen un acto de militancia. Sin embargo, varios de los elementos enlistados son generales y no queda claro cómo operarían en la práctica.

Ejemplo de lo anterior son los siguientes derechos: "c) El derecho a la discrepancia, al libre pensamiento y a la libre expresión de las ideas y f) El derecho a la capacitación y al adiestramiento políticos" (Código Electoral, art. 53). Según el voto aquí analizado, ejercer libertad de expresión sobre ideas de un partido político generaría un vínculo con ese partido, incluso si se expresaran discrepancias. Tampoco queda claro, más aún en la era de virtualización, si una persona que se conecta a un foro organizado por un partido estaría ejerciendo el derecho a la capacitación y adiestramiento 


\section{DERECHO ELECTORAL}

político y, por lo tanto, generando una militancia con el partido correspondiente.

Lo anterior sucede igual con las obligaciones propias de militantes de estructuras partidarias, se ejemplifica a continuación: "a) Compartir las finalidades del partido y colaborar en su consecución" (Código Electoral, art. 54). Cualquier persona que simpatice con el partido y vote por él o se manifieste públicamente a su favor en una contienda específica estaría cumpliendo esa obligación y se podría suponer un acto de militancia.

De esta forma, no queda claro cuáles actuaciones suponen militancia, y las personas, partidos e incluso el propio Tribunal se verían imposibilitados a aplicar lo señalado en el voto 2434-E8-2021.

Adicionalmente, al no existir disposición legal alguna sobre la creación de este vínculo con los partidos políticos, resulta difícil que todas las personas tengan claras las implicaciones de generar un vínculo de militancia con un partido político. Por ejemplo, una persona que quiera donar dinero a una campaña específica estaría aceptando también todos los deberes y derechos que el estatuto del partido respectivo consagra para sus militantes, sin siquiera saber cuáles son.

Un elemento adicional es el que corresponde al registro de militantes. Es esperable que cada partido político sostenga un registro de quiénes son las personas que ostentan la condición de miembros. Incluso, la falta de este registro implica que cualquier persona pueda participar como miembro del partido. Esto lo definió el propio Tribunal en sentencia 1512-E1-2009 resolviendo en el siguiente sentido:

Por estas cuatro razones se tiene como hecho no probado la existencia de un registro de militantes actualizado... Así, siendo que el Partido... no exhibió, conforme fue requerido por esta Autoridad, su libro o registro de militantes, no puede esa agrupación, con base en el elemental principio de seguridad jurídica del Estado de Derecho, exigirle a los ciudadanos acreditar una condición de militancia cuyo registro partidario se desconoce y que, para este Tribunal, es de existencia incierta. (Considerando IV).

Al no existir claridad específica en las acciones que implican un vínculo de militancia con una agrupación política, sería verdaderamente imposible para los partidos políticos llevar estos registros de manera fiable, y 


\section{DERECHOELECTORAL}

también vacía de contenido la propia militancia partidaria al no poder verificarse con criterios objetivos.

\section{Diseño constitucional en CUANTO A NiVeles de gobierno}

La historia de los partidos de escala cantonal antecede la propia Constitución, ya que en la Ley de Elecciones de 1932 se incluye la figura jurídica, pero no es sino hasta 1948 que se inscriben los primeros, y hasta 1953 comienzan a participar efectivamente en procesos electorales (Blanco, 2002).

Sin embargo, el régimen municipal fortalecido que se conoce en la actualidad sí quedó establecido en la Constitución de 1949, momento en el que se pretendió fortalecer las representaciones locales y alejarlas de los intereses nacionales.

En un recuento histórico de la inclusión del régimen municipal en Costa Rica realizado por Jiménez (1956), se señaló que la Constitución que rigió en la mayor parte del periodo comprendido desde 1871 y hasta 1949 se caracterizó por un abuso del centralismo y, por lo tanto, un debilitamiento de las municipalidades.

Este asunto fue de conocimiento de la Asamblea Nacional Constituyente de 1949, en la cual varios diputados se refirieron al papel de las municipalidades en el sistema de gobierno y los alcances de su autonomía. Al respecto, se citarán algunas intervenciones que dieron como resultado el texto actual sobre régimen municipal en la carta magna.

El representante Chacón Jinesta [...] Dijo que la autonomía municipal en Costa Rica nunca había existido, ya que las municipalidades siempre han estado supeditadas al Poder Ejecutivo por una serie de funcionarios y organismos. Si se desea realmente otorgar a las municipalidades su plena autonomía, deben desligarse del Ejecutivo.

El representante Baudrit Solera... De ahí que el interés ciudadano por el gobierno local se ha ido perdiendo poco a poco en nuestro país. Por todos lados las municipalidades se ven obstruccionadas por el Ejecutivo, que interviene en las mismas a través de una serie de funcionarios y organismos. Es tan poco 


\section{DERECHO ELECTORAL}

el interés que despiertan, que las funciones de munícipe se desempeñan con desgano. Es necesario que los ciudadanos se interesen más por los asuntos locales, creando la verdadera autonomía del régimen municipal (Asamblea Nacional Constituyente, citada en Saborío, 2005, Acta 80).

A estas intervenciones se le pueden sumar otras como la del diputado Zeledón, sobre las "disposiciones acerca de la autonomía del régimen municipal, que tienden a que las Municipalidades vuelvan a ser lo que eran en el pasado" (Asamblea Nacional Constituyente, citada en Saborío, 2005, Acta 59), o la del diputado Monge Ramírez en el acta 81.

Como se puede observar, la creación del régimen municipal en la Constitución de 1949 busca aumentar la participación en asuntos locales y alejarlos de los intereses de los gobiernos de turno. Precisamente, este ha sido un reto que aún hoy no se ha resuelto. Si bien en la última década se ha disminuido el abstencionismo en comicios locales, para el 2020 seguía rondando el 63,7\% (Tribunal Supremo de Elecciones, 2020).

En su motivación, el Tribunal señaló la resolución 3146-E-2000, en cuanto a que la última reforma constitucional al artículo 96 que se dio "en orden a promover a los partidos como entes permanentes que vivifiquen la democracia costarricense y que sirvan como instrumentos básicos para la participación política y no simples maquinarias electorales" (TSE, 2434-E8-2021, considerando II). Esta acción es una de las tantas que pretende fortalecer la participación ciudadana en asuntos públicos.

Sin embargo, no se considera la diversidad de intereses que persiguen los partidos en distintas escalas. Un gobierno municipal está llamado a preocuparse por los asuntos de su localidad, así mismo consta en el acta 55 de la Asamblea Nacional Constituyente, en la cual el diputado Baudrit Solera se refiere a esto de la siguiente forma:

Tampoco es cierto, continuó diciendo, que el representante de una localidad sea una especie de Cónsul de sus electores ante los órganos de gobierno. De aprobarse el capítulo referente al régimen municipal del proyecto del 49 , las municipalidades, libres y autónomas, robustecidas, serán las llamadas a preocuparse por los asuntos de su localidad, por el bienestar comunal, por el auge de la provincia o del 


\section{DERECHO ELECTORAL}

cantón [Resaltado no es del original]. (Asamblea Nacional Constituyente, como se cita en Saborío 2005, Acta 55).

Esto es congruente con el papel de los partidos políticos locales, quienes persiguen el bienestar de una comunidad específica a través de discusiones, capacitación y otras acciones políticas. Pero, al no tener estructuras fuera de la localidad, y al no poder postular personas a cargos de gobierno nacional, les sería imposible tener el mismo nivel de incidencia fuera de su respectivo cantón. De hecho, el propio Código Electoral establece que "los partidos políticos tendrán carácter cantonal cuando se inscriban únicamente para participar en la elección de cargos municipales del cantón" [Resaltado no es del original]. (Código Electoral, art. 51).

Fortalecer la participación en asuntos de interés local requiere acciones que faciliten la participación de las personas, no que la disuada. En ese sentido, el propio Tribunal Supremo de Elecciones propuso en el texto original de reforma al Código Electoral establecer "grupos independientes" que pudieran postular a personas a cargos de elección popular a nivel municipal; al respecto, indicaron lo siguiente: "Se permite a los ciudadanos organizarse en grupos independientes para participar en las elecciones a nivel municipal, rompiendo, de esa manera, el monopolio de los partidos políticos" (TSE, 2001, p. 4).

Si bien la propuesta anterior no fue acogida en la versión final del Código Electoral, promulgado en 2009, se evidencia un momento en el que el Tribunal partía de interpretaciones extensivas para fortalecer la participación política práctica y la vida democrática. Además, esta propuesta generó reacciones interesantes en el trámite legislativo, por ejemplo, resalta la intervención de la diputada Zamora Castillo en la sesión n. ${ }^{\circ} 25$ del 27 de julio de 2004 de la comisión especial designada para el estudio de este proyecto. En ese momento, la diputada señaló que:

...aquí en Costa Rica definitivamente el sistema democrático a [sic] cambiado, la gente piensa diferente, la gente incluso, es interesante ver cómo ya, por ejemplo, no era aquella vieja historia de que la gente votaba porque el papá era del partido y que porque había sido esto y había sido lo otro sino que la gente ya se... independiza su criterio y yo creo que eso es una 


\section{DERECHOELECTORAL}

manera de que nosotros, esto es una iniciativa para cargos municipales.

...Venimos de zona rural y una de las cosas que suceden en los pueblos es el desarraigo que hay entre los regidores y su misma comunidad. (Asamblea Legislativa, Acta 25 de la Comisión especial conocerá y dictaminará el expediente $n .^{\circ}$ 13.862, Ley de partidos políticos", expediente n.¹5.434, 2001, pp. 1186-1187).

En las mismas actas se puede apreciar que el criterio de la diputada era ampliamente compartido por los miembros de la comisión, donde el tema de una posible inconstitucionalidad fue lo que finalmente fundamentó la exclusión de los grupos independientes en el nuevo Código Electoral.

Se reconoció en ese entonces, al igual que se hizo en la Constituyente de 1949, que la participación política ha evolucionado y que se debe fortalecer la participación de las personas en los temas de interés local.

Sin embargo, en el caso del voto 2434-E8-2021, se genera una interpretación restrictiva a lo que el Tribunal llama "militancia fragmentada" para procesos electorales concretos. De esta forma, quienes tengan intereses en lo local y quieran formar parte de estructuras partidarias en una agrupación política de escala cantonal se verían cubiertos por una especie de prohibición de participar en una gran cantidad de actividades en procesos electorales nacionales, so pena de desvincularse de su estructura cantonal.

Cabe resaltar, además, que esta prohibición no tiene origen expreso en la ley o la Constitución, pues se define mediante la interpretación del Código Electoral en la jurisprudencia. Esta resolución afecta las estructuras cantonales al disuadir a personas de conformar sus estructuras porque puedan tener algún interés en procesos nacionales, aunque los partidos cantonales no participen en estos comicios.

Esto, además, es contrario al artículo 48 del Código Electoral en lo que se cita:

Ninguna norma o disposición de este Código se interpretará en el sentido de debilitar el papel constitucionalmente asignado a los partidos políticos como expresión del pluralismo político, 


\section{DERECHO EIECTORAL}

formadores de la manifestación de la voluntad popular y vehículos de la participación ciudadana en la política nacional.

De igual forma, el Tribunal Supremo de Elecciones, en el voto 1440-E2000, amplió en cuanto a que: "el derecho de los ciudadanos a agruparse en partidos es un derecho de libertad que obliga a los partidos a estimularlo, erradicando de su seno cualquier decisión tendiente a imponer medios disuasivos o indirectos que pudieran causar un efecto contrario" (TSE, 2000, considerando VII).

El Tribunal, en el voto que aquí se analiza, realiza una interpretación restrictiva sobre el pluralismo, y comunica a las personas que si desean apoyar un proyecto político nacional en una elección concreta, únicamente lo pueden hacer desvinculándose de cualquier estructura cantonal.

De esta forma, el Tribunal no debe establecer obstáculos a quienes sostienen un vínculo con un partido cantonal de participar en actividades de un proceso electoral nacional concreto. Más bien, al hacerlo, se debilitan las estructuras de los partidos cantonales en todo el país y se les impide cumplir sus funciones permanentes cuando existan elecciones nacionales en curso.

Adicionalmente, en la motivación, la autoridad electoral indicó que el partido solicitante incurrió en una imprecisión al "reducir los derechos políticos a formar parte activa de las estructuras partidarias" (Tribunal Supremo de Elecciones, 2021, considerando II).

Sin embargo, la resolución no se limita a restringir la pertenencia a estructuras partidarias, sino a ejercer cualquier tipo de acción que pueda entenderse como un acto de militancia: desde apoyar económicamente alguna candidatura en un proceso electoral hasta participar en actividades de campaña propias de un partido nacional (acciones ampliamente configuradas a partir de los artículos 53 y 54 del Código Electoral).

En este sentido, aún falta reflexión académica respecto de las implicaciones del título constitucional sobre "régimen municipal" y sobre la existencia de los partidos políticos de escala cantonal, los intereses que persiguen y el papel que deberían jugar en la creación de política pública. 


\section{DERECHO ELECTORAL}

\section{Conclusiones}

La forma en que las personas se vinculan con los partidos políticos ha cambiado mucho desde la redacción de la Constitución Política actual. Un elemento que siempre destaca es la apatía que existe actualmente hacia las estructuras partidarias. El Centro de Investigación y Estudios Políticos (CIEP) de la Universidad de Costa Rica encontró que: "solamente 13 personas de cada 100 manifiestan simpatizar con un partido político. En este escenario, la preferencia electoral y la intención de voto de las personas que sufragan son inciertas, volátiles y más vulnerables a factores o situaciones imprevistas" (CIEP, 2021, p. 18).

Esto ha tendido hacia un fenómeno que Martín (citado en Pineda, s.f. ) llama "personalización de la política". A través de las nuevas formas de comunicación que existen, las personas se identifican con candidaturas concretas y no con estructuras partidarias. El propio Tribunal reconoce esta realidad en el voto aquí analizado, indicando que:

...ciertamente, en la actualidad se logra observar una volatilidad de los electores (las preferencias políticas del votante cambian con facilidad) y una erosión de las lealtades partidarias (la permanencia en una misma agrupación por largo tiempo es cada vez menos frecuente). (TSE, 2021, considerando II).

Entonces, suponer el vínculo con toda la estructura partidaria por el apoyo de una persona a una candidatura en un proceso electoral concreto no solo es desfasado, sino que tiene una serie de implicaciones jurídicas para el partido y la persona que esta desconoce y que en la práctica no se vuelven ejecutables, como se desarrolló en el segundo apartado. Este configura el primer cuestionamiento al voto 2434-E8-2021 que quedó consagrado en la parte dispositiva, inciso A).

En cuanto a los incisos B) y C) de la parte dispositiva, se cuestiona la interpretación que realiza el Tribunal del papel de los partidos cantonales en la política nacional, puesto es materialmente imposible para los partidos al carecer de estructura fuera de su localidad y al oponerse a la intención del constituyente sobre el régimen municipal, según lo desarrollado en el tercer apartado.

De esta forma, la resolución 2434-E8-2021 constituye un retroceso en la descentralización de la política, debilita el papel constitucionalmente asignado a los partidos de escala cantonal y pone en riesgo los principios 


\section{DERECHO EIECTORAL}

de autorregulación partidaria y seguridad jurídica en cuanto a militancia partidaria se refiere.

Se recomienda ahondar la discusión académica en torno a los temas aquí esbozados, así como vincular la conceptualización actual del Tribunal Supremo de Elecciones con otros principios electorales que no se abordaron en el presente artículo por su alcance y formato. Asimismo, se considera oportuno profundizar en los estudios de vínculo de las personas con los partidos políticos en Costa Rica, que permitan enlazar la realidad práctica con las normas, de conformidad con las herramientas de interpretación hermenéutica de las que dispone el Tribunal.

\section{Referencias bibliográficas}

Aguilar, J. (2008). Identificación partidaria: apuntes teóricos para su estudio. Polis, 4(2), 15-46. Recuperado de http://www.scielo.org.mx/pdf/polis/v4n2/v4n2a2.pdf

Asamblea Legislativa. (2001). Acta n. ${ }^{\circ} 25$ del 27 de julio de 2004 de la Comisión especial que conocerá y dictaminará el expediente $n .^{\circ} 13.862$, Ley de partidos políticos, expediente n. ${ }^{\circ} 15.434$.

Asamblea Nacional Constituyente. (1949). Constitución Política de Costa Rica. Recuperado de https://www.pgrweb.go.cr/scij/Busqueda/Normativa/Normas/nrm_texto_c ompleto. aspx?nValor $1=1 \&$ nValor $2=871$

Blanco, R. (2002). Los partidos cantonales en las elecciones municipales de Costa Rica: 1949-2002. Una interpretación sociológica. Anuario de Estudios Centroamericanos, 161-186. Recuperado de https://www.redalyc.org/pdf/152/15228205.pdf

Centro de Investigación y Estudios Políticos, CIEP, de la Universidad de Costa Rica. (2021). Informe de resultados del estudio de opinión sociopolítica. Recuperado de https://ciep.ucr.ac.cr/wpcontent/uploads/2021/05/Informe-de-Resultados-del-Estudio-deOpinio\%CC\%81n-Sociopoli\%CC\%81tica-Abril-2021.pdf

Código Electoral. (2009). Ley 8765 del 19 de agosto. Publicada en el Alcance n. ${ }^{\circ} 37$ de La Gaceta n. ${ }^{\circ} 171$ del 2 de setiembre de 2009. Recuperado de https://www.tse.go.cr/pdf/normativa/codigoelectoral.pdf 


\section{DERECHO EIECTORAL}

Haba. E. P. (2007). Axiología jurídica fundamental. Bases de valoración en el discurso jurídico. 2a. edición. San José, Costa Rica: Editorial UCR. Recuperado de https://cijulenlinea.ucr.ac.cr/2009/la-seguridad-juridica/

Jiménez, A. (1956). Régimen municipal. Revista de la Universidad de Costa Rica. Recuperado, 90-96 https://revistas.ucr.ac.cr/index.php/ucr/article/download/20442/20653

Molina, J y Pérez, C. (2001). Participación política y derechos humanos. Revista del Instituto Interamericano de Derechos Humanos, 34-35. Recuperado de https://www.corteidh.or.cr/tablas/R08068-1.pdf

Partido Frente Amplio (Costa Rica) (2009). Estatuto Partido Frente Amplio. Recuperado https://www.tse.go.cr/pdf/normativa/estatutos/frenteamplio.pdf

Partido Restauración Nacional (Costa Rica). (2009). Estatuto Partido Restauración Nacional. Recuperado de https://www.tse.go.cr/pdf/normativa/estatutos/restauracionnacional.pdf

Pineda, A. (s.f.). Algunos elementos fundamentales del marketing electoral desde una perspectiva comunicacional. España: Universidad de Sevilla.

Saborío, R. (2005). Actas de la Asamblea Nacional Constituyente de Costa Rica, 1949. Versión 2005, revisada por el Dr. Rodolfo Saborío Valverde. San José, C.R.: Saborío \& Coto Abogados. Recuperado de https://www.rodolfosaborio.com/actas/ANC49.pdf

Sala Constitucional. (2010). Voto 15060-2010 de las catorce horas y cincuenta y dos minutos del ocho de setiembre. Recuperado de https://nexuspj.poderjudicial.go.cr/document/ext-1-0007-269917/undefined/0///2

Sala Constitucional. (1999). Voto 5367-99 de las diez horas treinta y nueve minutos del nueve de julio. Recuperado de https://www.tse.go.cr/juris/relevantes/SSC-5367-1999.htm

Sartori, G. (1999). Partidos y sistemas de partidos: marco para un análisis (Vol. 107). St. Martin's Press. Recuperado de https://ezequielsingman.files.wordpress.com/2017/03/sartori-partidos-ysistemas-de-partidos.pdf

Tribunal Supremo de Elecciones (1992). Voto 444 de las once horas con diez minutos del diecinueve de mayo. Recuperado de https://www.tse.go.cr/juris/electorales/0444-1992.HTM 


\section{DERECHO EIECTORAL}

Tribunal Supremo de Elecciones (2000). Voto 1440-E-2000 de las quince horas del catorce de julio. Recuperado de https://www.tse.go.cr/juris/electorales/1440-E-2000.HTM

Tribunal Supremo de Elecciones (2001). Acta n. ${ }^{\circ}$ 11-2001 de las quince horas del primero de febrero del dos mil uno.

Tribunal Supremo de Elecciones (2008). Voto 3261-E8-2008 de las nueve horas con cinco minutos del diecinueve de septiembre. Recuperado de https://www.tse.go.cr/juris/electorales/3261-E8-2008.html

Tribunal Supremo de Elecciones (2009). Voto 1512-E1-2009 de las catorce horas y treinta y dos minutos del tres de abril. Recuperado de https://www.tse.go.cr/juris/electorales/1512-E1-2009.htm

Tribunal Supremo de Elecciones (2012). Voto 8690-E8-2012 de las ocho horas treinta minutos del dieciocho de diciembre. Recuperado de https://www.tse.go.cr/juris/electorales/8690-E8-2012.html

Tribunal Supremo de Elecciones (2013). Voto 1257-E8-2013 de las once horas quince minutos del ocho de marzo. Recuperado de https://www.tse.go.cr/juris/electorales/1257-E8-2013.html

Tribunal Supremo de Elecciones (2020). Elecciones municipales en cifras 2002, 2020. Recuperado https://www.tse.go.cr/pdf/elecciones/eleccionesmunicipalescifras.pdf

Tribunal Supremo de Elecciones (2021). Voto 2434-E8-2021 de las diez horas del siete de mayo de dos mil veintiuno. 